\title{
Pruning of Manchurian Crabapple for Management of Speck Rot and Sphaeropsis Rot in Apple
}

\author{
Parama Sikdar \\ Department of Horticulture, Washington State University, Pullman, WA \\ 99164
}

\begin{abstract}
Mike Willett
Washington Tree Fruit Research Commission, 1719 Springwater Avenue, Wenatchee, WA 98801
\end{abstract}

\author{
Mark Mazzola ${ }^{1}$ \\ Tree Fruit Research Laboratory, USDA-Agricultural Research Service, 1104 \\ North Western Avenue, Wenatchee, WA 98801
}

Additional index words. Phacidiopycnis washingtonensis, Sphaeropsis pyriputrescens, postharvest

\begin{abstract}
Phacidiopycnis washingtonensis and Sphaeropsis pyriputrescens are fungal pathogens that cause postharvest speck rot and Sphaeropsis rot, respectively, in apple. Under quarantine regulations established by the Chinese government, export of apple from Washington State to China was banned between 2012 and 2014 because of detection of these pathogens in apple shipments. Previous studies established that pycnidia of $P$. washingtonensis and $S$. pyriputrescens survive in twig cankers on manchurian crabapple which serves as a dominant pollinizer in the Washington State apple industry. These pycnidia serve as a primary source of inoculum for infection of apple fruit in the orchard. The objective of this research was to conduct a study at multiple locations in Washington State to determine the efficacy of implementing manchurian crabapple pruning as a method to control speck rot and Sphaeropsis rot in storage. Four commercial orchards at geographically distant locations in Washington State were selected in 2014 and three in 2015. In 2014, two treatments included preharvest pruning of manchurian crabapple and postharvest application of pyrimethanil and untreated control. In 2015, preharvest pruning alone (PO) of manchurian crabapple was included in addition to the two treatments examined in 2014. Pruning conducted in concert with postharvest fungicide treatment significantly reduced the incidence of speck rot and Sphaeropsis rot in storage during the initial experimental field season. During year 2 , both the $P O$ and pruning with postharvest fungicide application controlled fruit rot with no significant difference between the two treatments. Findings from this study will be instrumental for the control of these postharvest diseases and maintenance of international market access for fruit from the Pacific Northwest.
\end{abstract}

\footnotetext{
Received for publication 2 Nov. 2017. Accepted for publication 15 Dec. 2017.

We thank Emmi Klarer, research intern at Washington State University, for her assistance in successful completion of all field and cold storage work. We also thank Tom Auvil, Manoella Mendoza, Ines Harharan, and field crew from the Washington Tree Fruit Research Commission, Wenatchee, for their assistance in pruning and harvest of trials. We thank Laura Grunefelder from Northwest Horticultural Council for her assistance in identifying trial orchards. We also thank Stefano Musacchi, Sara Serra, and Karen Lewis of Washington State University. We thank the Washington Tree Fruit Research Commission and the USDA-FAS-TASC program for financial support of this research.

Mention of a trademark, proprietary product, or vendor does not constitute a guarantee or warranty of the product by the U.S. Department of Agriculture and does not imply its approval to the exclusion of other products or vendors that also may be suitable.

${ }^{1}$ Corresponding author. E-mail: mark.mazzola@ ars.usda.gov.
}

Washington State is the largest producer of apple in the United States accounting for $\approx 60 \%$ of total production as of 2013 (NASS, 2012, 2015). Demand for Washington apples in the international market is high, and $\approx 30 \%$ of the total crop is exported (Globalwise Inc., 2014). Because of the availability of advanced fruit storage facilities in Washington State, the state's apple crop can be stored in cold rooms at $0{ }^{\circ} \mathrm{C}$ and controlled atmospheric (CA) condition for 9-12 months postharvest (Kupferman, 2003). However, fungal pathogens causing postharvest decay of apple can lead to a significant loss of fruit in storage resulting in economic losses (Kim and Xiao, 2006, 2008).

Phacidiopycnis washingtonensis and $S$. pyriputrescens causing speck rot and Sphaeropsis rot of apple, respectively, are two postharvest fungal pathogens recently determined to be of concern to the Washington apple industry (Kim and Xiao, 2006; Kim et al., 2013, 2014; Sikdar et al., 2014; Xiao et al., 2004, 2005, 2009). These pathogens incite latent infection of fruit in the orchard, and symptoms become apparent after 2-3 months of fruit storage in $\mathrm{CA}$ conditions (Kupferman, 2003) at -1 to $4{ }^{\circ} \mathrm{C}$, decreased oxygen $(1 \%$ to $2 \%)$, and increased carbon dioxide $(0.5 \%$ to $1 \%)$. The total incidence of decay due to these two pathogens is $\approx 4 \%$ to $5 \%$ annually (Kim and Xiao, 2008). These pathogens have been reported in the United States, Germany (Weber, 2011) and, very recently, Chile (Diaz et al., 2016). Several countries, including China and Australia, have raised quarantine concerns regarding these fungal species. Because of the interception of infected fruit in shipments bound for China, the General Administration of Quality Supervision, Inspection, and Quarantine of People's Republic of China (AQSIQ) imposed a complete ban on import of U.S. apples between 2012 and 2014 (Sikdar and Mazzola, 2015). The current work was undertaken as a result of an agreement between the USDA's Animal and Plant Health Inspection Service and AQSIQ to conduct "proof-of-concept" research in support of the systems approach which allowed the Chinese market to reopen to Washington apples.

Phacidiopycnis washingtonensis and $S$. pyriputrescens both infect manchurian crabapple fruit [Malus mandshurica (Maxim.) Kom. ex Juz.] and branches (Sikdar et al., 2013, 2014; Xiao and Boal, 2005; Xiao et al., 2009, 2014). Infected crabapple fruit often decay in the trees, turning into dark black fruit mummies. These fungi are also capable of causing cankers and dieback of crabapple twigs and branches. Pycnidia are produced on fruit mummies and the margins of cankers, thus serving as a potential source of inoculum in the orchard. Historically, Washington State has used manchurian crabapple as a pollinizer in apple orchards because of its timing of flowering and fruit set (Church and Williams, 1983; Crassweller et al., 1980; Williams and Church, 1983). Manchurian crabapple produces large and sharp spurs on its branches which can cause damage to farm equipment if pruned branches and twigs are left on the orchard floor. Hence, pruning of manchurian crabapple had been avoided to reduce potential economic losses caused by damage to farm machinery and potential injury to laborers. Because of the absence of pruning, crabapple pollinizers commonly occur in the orchard as bushy trees possessing pendant limbs often bearing dead and dying wood, diseased twigs, and fruit mummies, thereby providing a ready and abundant source of inoculum for fruit infection.

The objective of this research was to determine whether pruning of manchurian crabapple, removal of fruit mummies from the trees, and postharvest drench application of fungicide could effectively control the postharvest incidence of speck rot and Sphaeropsis rot over the course of the fruit storage season. 


\section{Materials and Methods}

Inoculum. All study sites possessed natural infections of fruit and twigs by the target pathogens, $P$. washingtonensis and $S$. pyriputrescens, with cankers and fruit mummies apparent on manchurian crabapple trees in the orchard. Infected crabapple twig samples and mummified fruit were collected from each location and tissue was excised from lesions and placed on potato dextrose agar (PDA) for isolation of potential causal pathogens. Fungal identity was confirmed using morphological description and spore morphology as previously described (Xiao et al., 2004, 2005). In the relatively large orchards used for this work, the manchurian crabapple pollinizers located outside of the experimental areas were left unpruned.

Orchard selection. In 2014, four commercial orchards located across the primary apple production region of central Washington State were selected viz., Malott (north), Quincy and Othello (central), and Yakima (south). Employment of four orchard sites allowed for use of geographically well-distributed locations and thus effective representation of the entire commercial apple-growing region in Washington State. In 2015, one orchard located in Quincy was not selected for inclusion in the study because of its proximity to the orchard in Othello and similarity in the incidence of decay observed at the two locations for fruit harvested in 2014. All study sites were planted with multiple apple varieties; however, only Red Delicious was selected for evaluation in our trial because it was the primary cultivar exported to China. In all orchards, manchurian crabapple which had not been pruned, historically, were used as pollinizers. Hence, there existed a high incidence of potential inoculum residing on twig cankers and fruit mummies of manchurian crabapple at these sites. At Malott $\left(48.2826^{\circ} \mathrm{N}, 119.7067^{\circ} \mathrm{W}\right)$, the trees were planted in 1993, with the scion grafted on MM. 111 rootstock. At Yakima $\left(46.6021^{\circ} \mathrm{N}\right.$, $\left.120.5059^{\circ} \mathrm{W}\right)$, the orchard was planted in 1983, with the Red Delicious scion; however, rootstock information is unknown. In both of these orchards, the pollinizer was interplanted at ten tree intervals in every alternate row. Orchards located at Quincy $\left(47.2343^{\circ} \mathrm{N}\right.$, $\left.119.8526^{\circ} \mathrm{W}\right)$ and Othello $\left(46.8260^{\circ} \mathrm{N}\right.$, $\left.119.1753^{\circ} \mathrm{W}\right)$ were more than 20 years old, but the exact year of planting and rootstock identity were unknown. In these orchards, the pollinizer was interplanted in every row, at 10-15 tree intervals. None of the orchards received any preharvest spray in the blocks where trials were conducted.

Experimental design. Trials were conducted in two consecutive growing seasons during 2014 and 2015. Manchurian crabapple trees possessing an ample source of natural inoculum were identified in all four of the selected orchards. In 2014, disease management method incorporated pruning and fungicide (PF) treatment, i.e., preharvest pruning of manchurian crabapple and application of a postharvest fungicide drench of fruit that were harvested from trees adjacent to the pruned manchurian crabapple. Efficacy of the approach was compared with the untreated control (C). In 2015, studies were conducted to determine whether pruning of manchurian crabapple without the addition of a postharvest fungicide application could effectively control postharvest speck rot and Sphaeropsis rot. This trial included the following treatments: the PF treatment as described previously, PO treatment that encompassed pruning of manchurian crabapple without postharvest fungicide application on fruit harvested from apple trees adjacent to pruned manchurian crabapple, and the untreated control (C). Each treatment was represented by four replications, eight trees per replicate, and 20 fruit per tree constituting a total of 160 fruit per replicate. For a given replicate, 20 fruit were harvested randomly from all eight trees. At all locations, a replicate consisted of a tree row in which manchurian crabapple pollinizers were interplanted. At Malott, the trees that received PF treatment in 2014 and 2015 and PO treatment in 2015 were separated from the trees that received untreated control (C) by a buffer area consisting of four rows of trees. A similar buffer zone of four tree rows was used to separate the PF and PO treatments in the orchard block. At Quincy, Othello, and Yakima, each treatment row i.e., $\mathrm{PF}, \mathrm{PO}$, and $\mathrm{C}$, was separated by four rows of buffer trees to avoid interference. At all locations, the manchurian crabapple trees were pruned using a chain saw for $\mathrm{PF}$ treatment in 2014 and PF and PO treatments in 2015. All visibly infected crabapple twigs were removed by pruning, any horizontal pendant twigs were also removed, and the leader branch was allowed to grow vertically pointing upward. Pruning was conducted between the first and second week of May soon after the first petal fall. Fruit harvest was conducted on the commercial harvest dates i.e., on 3 Sept. 2014 for Malott, 4 Sept. 2014 for Quincy, 8 Sept. 2014 for Othello, and 10 Sept. 2014 for Yakima. In the second year i.e., 2015, fruit were harvested on the following commercial dates: 14 Sept. 2015 for Malott, 16 Sept. 2015 for Othello, and 23 Sept. 2015 for Yakima. Fruit for PF treatment were drenched at a commercial facility before storage with the fungicide pyrimethanil at the application rate of $2390 \mathrm{mg} / \mathrm{L}$ of commercial formula, which is equivalent to $1000 \mathrm{ppm}$ of active ingredient. All fruit were then stored at $0{ }^{\circ} \mathrm{C}$ under regular atmospheric conditions for a period of 8 months postharvest in a commercial fruit storage warehouse.

Methodology. Fruit were inspected to determine the incidence of rot starting from 15 , 30,45 , and $60 \mathrm{~d}$ postharvest and then every month through 8 months postharvest. On each day of inspection, the number of fruit showing symptoms was recorded and symptomatic fruit were removed from the fruit lot. The symptomatic fruit were brought back to the laboratory for isolation of causal pathogens. Symptomatic fruit were surface disinfested using $70 \%$ ethanol. Symptomatic tissue around the stem end, calyx end, or margin of lesions on skin was excised using a sterile scalpel and then transferred onto PDA. Culture plates were incubated at $20{ }^{\circ} \mathrm{C}$ in dark for $5 \mathrm{~d}$ and emergent hyphal growth was examined under a light microscope $(100 \times)$. The causal pathogens were identified by comparing the hyphal growth and morphology to that of $P$. washingtonensis and $S$. pyriputrescens as previously described (Xiao et al., 2004, 2005).

Data analysis. Incidence of rot was determined for stored fruit at 8 months postharvest
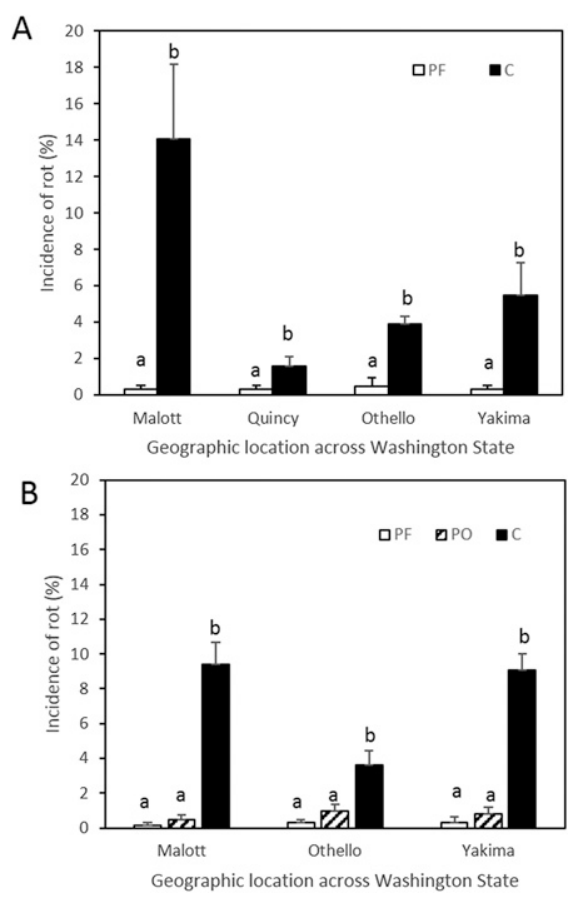

Fig. 1. Effect of sanitation pruning of manchurian crabapple pruning plus postharvest application of fungicide (PF) treatment to Red Delicious apple or pruning only (PO) treatment on incidence of postharvest fruit rot caused by Phacidiopycnis washingtonensis and Sphaeropsis pyriputrescens detected after an 8-month cold storage $\left(0{ }^{\circ} \mathrm{C}\right)$ in regular atmosphere: (A) 2014-15 and (B) 2015-16. Trials were conducted at orchards in Malott, Quincy, Othello, and Yakima, WA during 2014. In 2015, trials were conducted at three orchards located in Malott, Othello, and Yakima, WA. In 2014-15, PF treatment was compared with an untreated control (C). Fruit for PF treatment were drenched at a commercial facility before storage with the fungicide pyrimethanil at the commercial application rate of $2390 \mathrm{mg} / \mathrm{L}$ of commercial formula. The bar represents the mean percentage of rot at the end of 8 months postharvest in storage resulting from natural infections in the field. Fruit harvested from Malott expressing postharvest symptoms in storage yielded only $S$. pyriputrescens in isolations from fruit lesions, whereas $P$. washingtonensis was isolated from symptomatic diseased fruit recovered from Othello, Quincy, and Yakima. Statistical analysis was performed within each grower lot. Means labeled with the same letter do not differ significantly $(P \leq$ 0.05 ) based on Fisher's protected least significant difference. 
for each treatment and each location. Incidence data were transformed arcsin [square root $(x)$ ] before analysis. For each location, differentiation of treatments were analyzed using analysis of variance and Fisher's protected least significant difference $(P=0.05)$ in SAS PROC GLM (Version 9.4; SAS Institute, Cary, NC).

The progression of fruit rot during the storage season was also recorded by inspection date, and a disease progression curve for each treatment over the total time in storage was also analyzed.

\section{Results}

Effect of crabapple PF drench on incidence of postharvest rot. In 2014, the percentage of fruit-bearing symptoms of speck rot and Sphaeropsis rot in total at all three locations was significantly lower
$(P=0.0006)$ when manchurian crabapple trees were pruned and the fruit treated with fungicide $(\mathrm{PF})$ compared with the untreated control (C). The total rot in control (C) Red Delicious apples were $14.06 \% \pm 4.13 \%, 1.56 \% \pm 0.54 \%$, $3.90 \% \pm 0.39 \%$, and $5.46 \% \pm 1.79 \%$ from Malott, Quincy, Othello, and Yakima, respectively. In 2014, the PF treatment reduced the total rot to only $0.31 \% \pm 0.18 \%$ in fruit harvested from Malott, Quincy, and Yakima and to $0.46 \% \pm 0.20 \%$ in fruit harvested from Othello (Fig. 1A).

In 2015, pruning of manchurian crabapple in concert with postharvest fungicide treatment $(\mathrm{PF})$ of harvested fruit was effective in controlling postharvest incidence of speck rot and Sphaeropsis rot at all three locations. However, there was no significant difference $(P=0.67)$ between the PF treatment and the PO treatment at all three locations. The total percentage of rot was reduced from
$9.37 \% \pm 1.3 \%$ to $0.47 \% \pm 0.29 \%$ for the treatment $\mathrm{PO}$ and $0.15 \% \pm 0.15 \%$ for the PF treatment at Malott (Fig. 1B). At the Othello orchard, fruit rot was reduced from $3.6 \% \pm$ $0.821 \%$ to $0.94 \% \pm 0.40 \%$ for the PO treatment and $0.31 \% \pm 0.18 \%$ for PF treatment. Similarly, at Yakima, total fruit rot at 8 months postharvest was reduced from $9.06 \%$ $\pm 0.97 \%$ to $0.78 \% \pm 0.39 \%$ of fruit harvested from PO treatment and $0.31 \% \pm 0.31 \%$ for fruit that were harvested from the PF treatment (Fig. 1B).

Disease progress in storage. In both growing seasons, symptom development caused by either $S$. pyriputrescens or $P$. washingtonensis was not observed in stored fruit until $45 \mathrm{~d}$ postharvest. The incidence of speck rot and Sphaeropsis rot was greatest at $120 \mathrm{~d}$ postharvest for fruit harvested from control plots at Malott and Othello orchards (Figs. 2 and 3). For fruit collected from
A
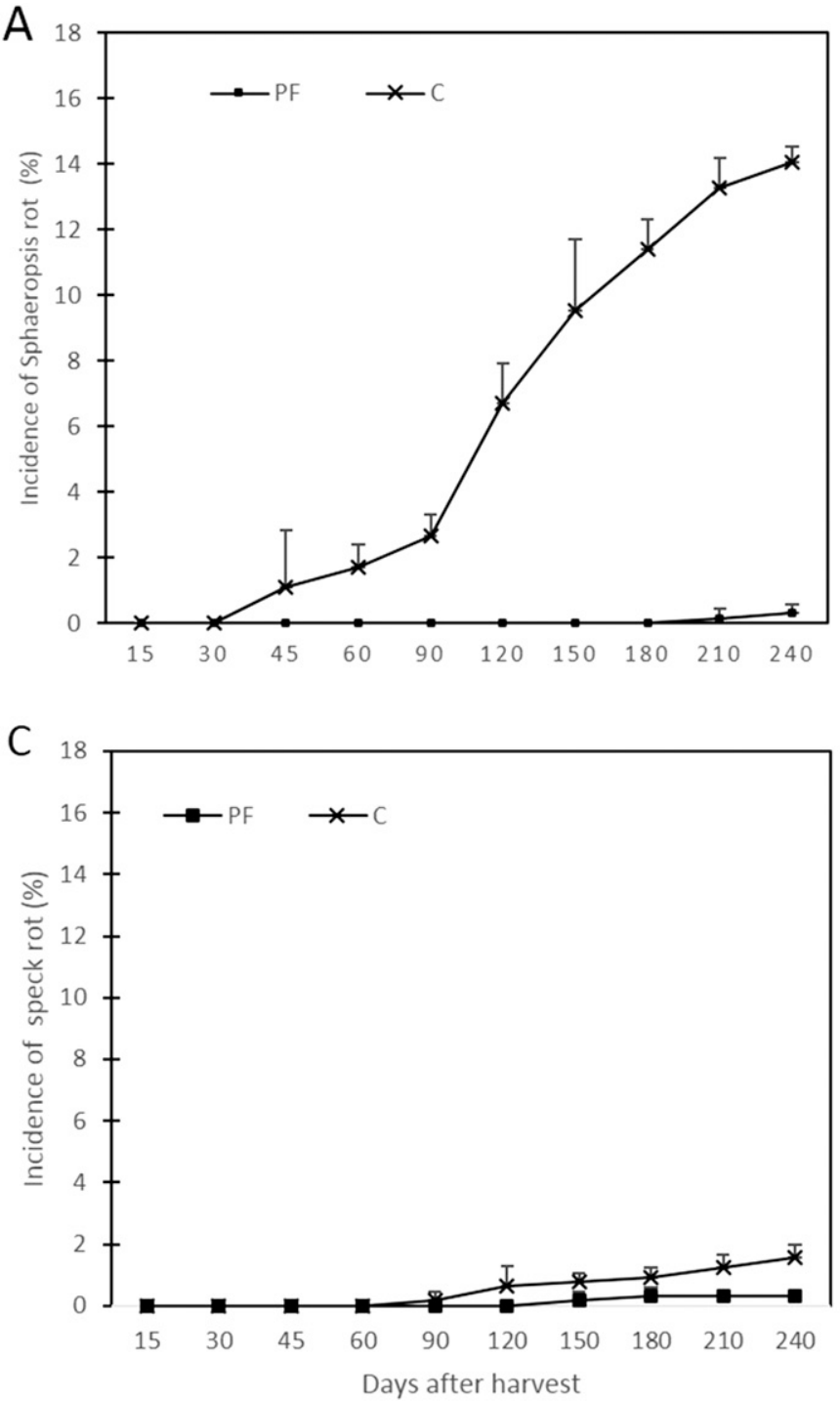

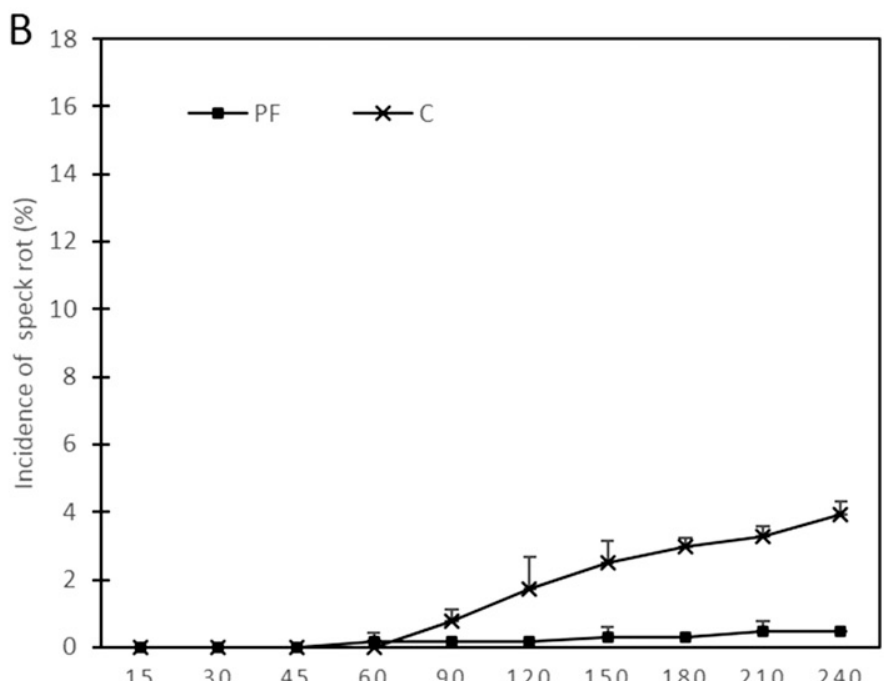

D

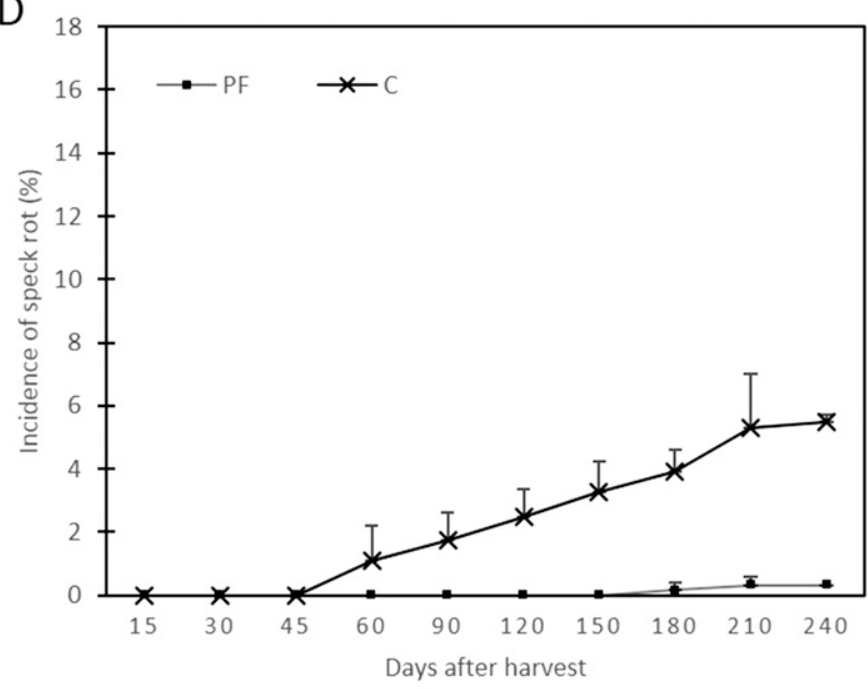

Fig. 2. Progression of postharvest rot of Red Delicious apple caused by Phacidiopycnis washingtonensis and Sphaeropsis pyriputrescens in 2014-15. Red Delicious apple were stored in cold storage $\left(0^{\circ} \mathrm{C}\right)$ in regular atmosphere. Red Delicious apple were harvested from (A) Malott, (B) Othello, (C) Quincy, and (D) Yakima, WA and either were untreated control (C) or received the systems treatment which included preharvest pruning of manchurian crabapple and postharvest fungicide application (PF). PF treatment fruit were drenched at a commercial facility before storage with the fungicide pyrimethanil at the recommended application rate of $2390 \mathrm{mg} / \mathrm{L}$ of commercial formula. Sphaeropsis pyriputrescens was recovered from diseased fruit harvested from the Malott orchard, whereas $P$. washingtonensis was isolated from symptomatic fruit recovered from Othello, Quincy, and Yakima orchards. 
Yakima the symptoms appeared at $60 \mathrm{~d}$ postharvest (Figs. 2D and 3C). At all locations, additional types of postharvest rot were detected including grey mold and blue mold caused by Botrytis cinerea and Penicillium spp., respectively. Sphaeropsis pyriputrescens, but not $P$. washingtonensis, was recovered from all symptomatic fruit collected at Malott in 2015 with additional postharvest

A

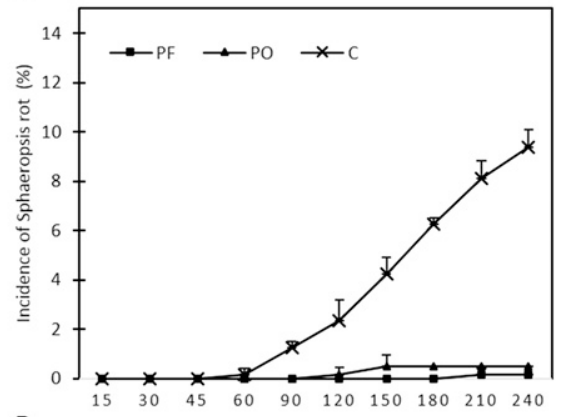

B
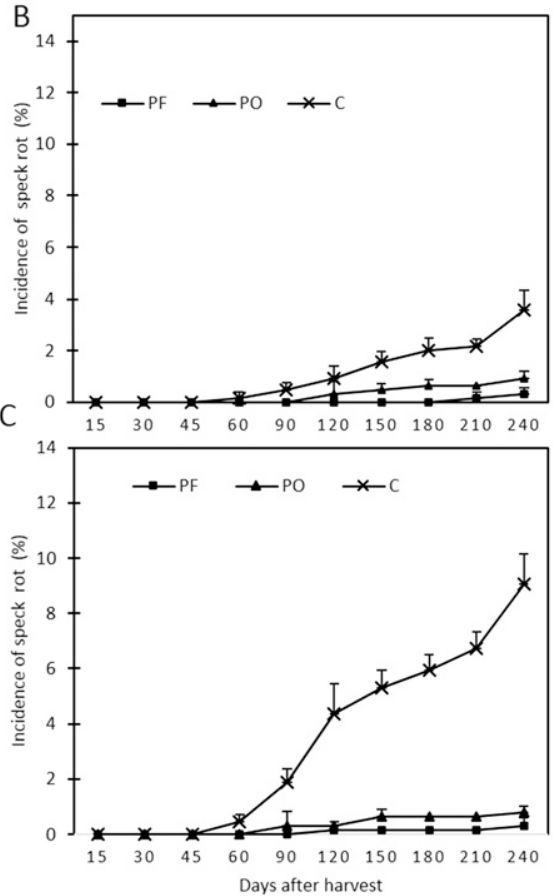

Fig. 3. Progression of postharvest rot of Red Delicious apple caused by Phacidiopycnis washingtonensis and Sphaeropsis pyriputrescens in 2015-16. Red Delicious apple were stored in cold storage $\left(0{ }^{\circ} \mathrm{C}\right)$ in regular atmosphere. Red Delicious apple were harvested from orchards in (A) Malott, (B) Othello, and (C) Yakima, WA and receiving the pruning and fungicide (PF; preharvest manchurian crabapple pruning and postharvest fungicide application of apple), pruning only treatment (PO; preharvest pruning of manchurian crabapple with no postharvest fungicide), or untreated control (C). PF treatment fruit were drenched at a commercial facility before storage with the fungicide pyrimethanil at the recommended application rate of $2390 \mathrm{mg} / \mathrm{L}$ of commercial formula. Sphaeropsis pyriputrescens was recovered from diseased fruit harvested from the Malott orchard, whereas $P$. washingtonensis was isolated from symptomatic fruit recovered from Othello, Quincy, and Yakima orchards. pathogens such as B. cinerea and Penicillium spp. detected infrequently. Phacidiopycnis washingtonensis was the primary postharvest pathogen isolated from fruit harvested at Yakima, Othello, and Quincy (Figs. 2 and 3) along with other commonly occurring postharvest pathogens.

\section{Discussion}

In previous surveys, it was determined that $P$. washingtonensis and $S$. pyriputrescens accounted for $4-5 \%$ of the total fruit lost because of postharvest fruit rot in the Washington State apple production system (Kim and Xiao, 2006, 2008; Kim et al., 2014; Xiao and Kim, 2008). Our current studies conducted in commercial orchards indicate that the total percentage of storage rot caused by these two pathogens could be as high as $14 \%$ in the absence of postharvest fungicide application or the pruning of pollinizers that harbor inoculum of these fungal pathogens. This level of infection could be a significant economic threat to the tree fruit industry and warrants implementation of effective control methods. In our study, we validated that pruning of manchurian crabapple trees significantly reduced the incidence of both speck rot and Sphaeropsis rots at all locations. Findings from the 2014 to 2015 trial demonstrated that pruning of manchurian crabapple trees conducted in concert with postharvest fungicide application can significantly reduce the incidence of postharvest speck rot and Sphaeropsis rot from as high as $14 \%$ to $0.31 \%$. Although susceptibility of manchurian crabapple and apple to infection by these pathogens was previously reported, there was no prior demonstration of pollinizer pruning as an effective method to reduce the incidence of postharvest speck rot and Sphaeropsis rot (Kim et al., 2014; Xiao and Boal, 2005; Xiao et al., 2009, 2014). The findings in the current study provide the first validation regarding the importance of sanitation pruning of manchurian crabapple for effective management of both speck rot and Sphaeropsis rot during postharvest storage of apple. As a result, it is now mandatory to prune manchurian crabapple pollinizers for all orchards registered to export fruit to China, and the results from the current studies played a key role in the implementation of the pruning mandate that led to reopening of the Chinese market in early 2015 to U.S. apples (Courtney and Mullinax, 2016).

Infection of apple by $P$. washingtonensis and $S$. pyriputrescens occur while the fruit is developing in the orchard during the entire growing season (Kim et al., 2014; Sikdar et al., 2014). The source of inoculum for fruit infection is usually viable pycnidia present on infected twigs of apple and crabapple trees or mummified crabapple fruit possessing visible fruiting bodies (Sikdar and Mazzola, 2015; Sikdar et al., 2014; Xiao et al., 2009, 2014). Prolonged periods of moisture availability as experienced during the typically wet periods of winter or spring is the most critical time for the spread of water dispersed spores from pycnidia. Hence, we tested pruning of manchurian crabapple in late spring just after petal fall as the wet climate in spring is conducive for early infection of apple fruit in the orchard. Results from our study demonstrated significant reduction in the incidence of postharvest rot due to $P$. washingtonensis and $S$. pyriputrescens, thereby validating the effectiveness of cultural practices in controlling inoculum and subsequent infection.

Previous studies demonstrated that postharvest fungicide applications can effectively control the incidence of speck rot and Sphaeropsis rot in apple (Xiao and Boal, 2014; Xiao et al., 2011). In this study, we sought to determine whether preharvest PO without a postharvest fungicide would control the incidence of decay. During the 2015-16 growing and storage season the PO treatment was as effective as the PF treatment at all three study orchards. Pruning alone treatment reduced the incidence of decay from $9 \%$ to $0.47 \%$. These findings indicate that the PO treatment may be a viable approach to control these two quarantined postharvest pathogens in organic orchard systems; a production system that represents an increasing component of the total industry in Washington. However, implementation of the PO treatment in this trial was conducted by individuals with intimate knowledge of these two fungal pathogens and thus resulted in detailed treatment application that may not consistently be applied by less-trained orchard staff. In addition, the fruit from the PO treatment exhibited the development of other postharvest rots including blue mold and grey mold which indicate the commercial value of the additional fungicide treatment in an overall postharvest disease management program. These additional postharvest diseases are not the subject of quarantine restrictions and, thus, may be controlled in conventional production systems by application of postharvest fungicides. Both PF and PO treatments significantly reduced the incidence of speck rot and Sphaeropsis rot in storage and there was no significant difference in the effect of these treatments in management of the two diseases. Although PO treatment of manchurian crabapple in conventional and organic orchards without postharvest fungicide treatment could significantly reduce incidence of speck rot and Sphaeropsis rot in storage, addition of the fungicide treatment in conventional systems provides additional insurance regarding the effective management of these important quarantined pathogens.

Pruning of manchurian crabapple is a labor and cost-intensive procedure, as growers need to haul pruned material out of the orchard to avoid inoculum buildup or damage to farm equipment. Thus, it is also important to examine the spectrum of potential disease resistance among pollinizers suitable for replacing manchurian crabapple. Such a replacement pollinizer would need to possess several additional characteristics including high pollen viability, flowering time that 
overlaps with numerous commercial apple cultivars, and resistance to commonly occurring apple diseases including perennial canker (Neofabraea sp.), fire blight (Erwinia amylovora), and powdery mildew [Podosphaera leucotricha (Ell. and Ev.) Salm]. Screening of potential pollinizer germplasm is currently ongoing in Wenatchee, WA. Until a replacement of manchurian crabapple is reported from subsequent studies, results from the studies described here justify the implementation of manchurian crabapple pruning programs for controlling speck rot and Sphaeropsis rot in storage.

\section{Literature Cited}

Church, R.M. and R.R. Williams. 1983. Comparison of flowering dates and pollen release characteristics of several Malus cultivars used as pollinators for Cox's orange pippin apple. J. Hort. Sci. 58:349-353.

Courtney, R. and T.J. Mullinax. 2016. Getting to the rot of the problem. Good Fruit Grower. 25 Feb. 2017. <http://www.goodfruit.com/gettingto-the-rot-of-the-problem/>.

Crassweller, R.M., D.C. Ferree, and L.P. Nichols. 1980. Flowering crabapples, a potential pollinizers for commercial apple cultivars. J. Amer. Soc. Hort. Sci. 105:475-477.

Diaz, G.A., J.P. Zoffoli, M. Lolas, A. Blanco, B.A. Lotorre, E.E. Ferrada, K. Elfar, and P. Naranjo. 2016. Occurrence of Phacidiopycnis washingtonensis causing speck rot on stored pink lady apple fruit in Chile. Plant Dis. 100:211.

Globalwise Inc. 2014. Updated evaluation of contributions to the state economy and the important role of exports. The Washington Apple Industry, Vancouver, WA and Belrose Inc., Pullman, WA. 20 Feb. 2016. <http://www.yvgsa.com/pdf/facts/ Economic\%20Impact\%20Study.pdf $>$.
Kim, Y.K., R. Caiazzo, P. Sikdar, and C.L. Xiao, 2013. First report of Sphaeropsis rot of apple caused by Sphaeropsis pyriputrescens in New York. Plant Dis. 97:1257.

Kim, Y.K., E.A. Curry, and C.L. Xiao. 2014. Infection of apple fruit by Sphaeropsis pyriputrescens in the orchard in relation to Sphaeropsis rot in storage. Eur. J. Plant Pathol. 140:133-143.

Kim, Y.K. and C.L. Xiao. 2006. A postharvest fruit rot in apple caused by Phacidiopycnis washingtonensis. Plant Dis. 90:1376-1381.

Kim, Y.K. and C.L. Xiao. 2008. Distribution and incidence of Sphaeropsis rot in apple in Washington state. Plant Dis. 92:940-946.

Kupferman, E. 2003. Controlled atmosphere storage of apples and pears. Acta Hort. 600:729-735.

National Agricultural Statistics Service. 2012. Value of Washington's 2011 agricultural production sets record high. 8 Dec. 2014. <http://www. nass.usda.gov/Statistics_by_State/Washington/ Publications/Current_News_Release/Top40_2012. pdf $>$.

National Agricultural Statistics Service. 2015. Value of Washington's 2013 agricultural production surpasses ten billion dollars. USDA-ARS. 20 Feb. 2016. <https://www nass.usda.gov/Statistics_by_State/Washington/ Publications/Current_News_Release/2015/VOP_ 2014.pdf>.

Sikdar, P. and M. Mazzola. 2015. Managing quarantine specific postharvest diseases in $\mathrm{Pa}-$ cific Northwest apple orchard. Phytopathology 105:S4.127 (abstr.)

Sikdar, P., M. Mazzola, and C.L. Xiao. 2013. Phacidiopycnis washingtonensis: Inoculum availability, persistence and seasonal host susceptibility in Washington orchard. Phytopathology 103:S2.133 (abstr.).

Sikdar, P., M. Mazzola, and C.L. Xiao. 2014. Infection courts and timing of infection of apple fruit by Phacidiopycnis washingtonensis in the orchard in relation to speck rot during storage. Plant Dis. 98:1467-1475.

Weber, R.W.S. 2011. Phacidiopycnis washingtonensis, cause of a new storage rot of apples in Northern Europe. J. Phytopathol. 159:682-686.

Williams, R.R. and R.M. Church. 1983. Growth and flowering of ornamental Malus pollinators in apple orchards. J. Hort. Sci. 58:337-342.

Xiao, C.L. and R.J. Boal. 2005. A new canker and twig dieback disease of apple and crabapple trees caused by Sphaeropsis pyriputrescens in Washington State. Plant Dis. 89:1130.

Xiao, C.L. and R.J. Boal. 2014. Control of speck rot in apple fruit caused by Phacidiopycnis washingtonensis with pre- and postharvest fungicides. Phytopathology 104:S3.132 (abstr.).

Xiao, C.L. and Y.K. Kim. 2008. Postharvest fruit rots in apples caused by Botrytis cinerea, Phacidiopycnis washingtonensis, and Sphaeropsis pyriputrescens. Online. Plant Health Prog., doi: 10.1094/PHP-2008-0919-01-DG.

Xiao, C.L., Y.K. Kim, and R.J. Boal. 2009. A new canker disease of crabapple trees caused by Phacidiopycnis washingtonensis in Washington state. Online. Plant Health Prog., doi: 10.1094/PHP-2009-0612-01-BR.

Xiao, C.L., Y.K. Kim, and R.J. Boal. 2011. Control of Sphaeropsis rot in stored apple fruit caused by Sphaeropsis pyriputrescens with postharvest fungicides. Plant Dis. 95:1075-1079.

Xiao, C.L., Y.K. Kim, and R.J. Boal. 2014. Sources and availability of inoculum and seasonal survival of Sphaeropsis pyriputrescens in apple orchards. Plant Dis. 98:1043-1049.

Xiao, C.L., J.D. Rogers, and R.J. Boal. 2004. First report of a new postharvest fruit rot on apple caused by Sphaeropsis pyriputrescens. Plan Dis. 88:223.

Xiao, C.L., J.D. Rogers, Y.K. Kim, and Q. Liu. 2005. Phacidiopycnis washingtonensis-A new species associated with pome fruits from Washington state. Mycologia 97:464-473. 